НЗВЕСТИЯ АКАДЕМИН НАУК ЭСТОНСКОП ССР. ТОМ 31 ХИМия. 1982, № 3

Евгения БОНДАРЬ, Вилья ПАЛУ, Р. ВЕСКИ

\title{
ОБ ИЗМЕНЕНИИ СОСТАВА ОРГАНИЧЕСКИХ КИСЛОТ БИТУМОИДОВ А И С САПРОПЕЛЯ ОЗЕРА ЛАХЕПЕРА В ЗАВИСИМОСТИ ОТ ГЛУБИНЫ
}

(Представил О. Эйзен)

Благодаря развитию современной аналитической техники, в первую очередь газовой хроматографии и масс-спектрометрий, в последние 15-20 лет достигнуты значительные успехи в идентификации органических соединений в современных озерных отложеннях [1]. Однако, в исследованиях этих отложений сапропелям, то есть отложениям с концентрированным органическим веществом $(\mathrm{OB} \geqslant 10 \%)$, отведено более чем скромное место, о чем можно судить по тому, что из ста пятидесяти шести источников, цитируемых в уже упомянутом обзоре [1], лишь три посвящены исследованию органических соединений сапропелей. Распространенностью сапропелевых отложений в озерах Эстонии, их малой изученностью, а также генетической связью сапропелевых отложений с сапропелитовыми горючими сланцами обоснован выбор объекта данных исследований - сапропеля послеледникового озера Лахепера (Восточная Эстония). Проведенная работа - логическое продолжение исследований группового состава сапропеля того же озера [ $\left.{ }^{2}\right]$.

Характеристика битумоидов

\begin{tabular}{|c|c|c|c|c|c|c|c|}
\hline \multirow{2}{*}{$\begin{array}{c}\text { Глубнна отбора проб } \\
\text { от поверхности воды, } \\
M\end{array}$} & \multirow{2}{*}{$\begin{array}{c}\text { Зола, } \\
\%\end{array}$} & \multirow{2}{*}{$\begin{array}{c}\text { Выход } \\
\text { от ОВ } \\
\text { сапро- } \\
\text { пеля, } \\
\%\end{array}$} & \multicolumn{4}{|c|}{ Әлементный состав ОВ, \% } & \multirow{2}{*}{$\mathrm{H} / \mathrm{C}$} \\
\hline & & & C & $\mathrm{H}$ & $N$ & $\begin{array}{c}\text { O } \\
\text { по раз- } \\
\text { ности }\end{array}$ & \\
\hline
\end{tabular}

$1,28-1,50$

$2,70-3,20$

$3,20-3,70$

$4,20-4,70$

$6,20-6,70$

$7,70-8,20$

$1,28-1,50$

$2,70-3,20$

$3,20-3,70$

$4,20-4,70$

$6,20-6,70$

$7,70-8,20$

В среднем 1,28-9,20
Битумоид А

\begin{tabular}{l|l|l|l|l|l|l}
2,63 & 7,0 & 72,8 & 10,5 & 1,5 & 15,2 & 1,74 \\
5,08 & 6,5 & 70,0 & 10,4 & 2,0 & 17,6 & 1,78 \\
1,63 & 5,9 & 73,9 & 10,3 & 1,2 & 14,6 & 1,67 \\
2,87 & 5,3 & 70,2 & 10,2 & 1,7 & 17,9 & 1,75 \\
2,82 & 6,0 & 72,6 & 10,5 & 1,6 & 15,3 & 1,73 \\
1,59 & 6,3 & 73,6 & 10,3 & 1,6 & 14,5 & 1,68
\end{tabular}

Битумоид С

\begin{tabular}{|l|l|l|l|l|l|l|}
0,64 & 3,0 & 69,1 & 9,5 & 2,1 & 19,3 & 1,68 \\
0,87 & 2,4 & 67,4 & 9,0 & 1,9 & 21,7 & 1,61 \\
1,00 & 2,6 & 68,4 & 9,2 & 2,0 & 20,4 & 1,61 \\
1,52 & 2,3 & 69,3 & 9,4 & 1,9 & 19,4 & 1,63 \\
0,92 & 4,1 & 64,5 & 8,2 & 2,8 & 24,5 & 1,52 \\
0,74 & 4,1 & 64,7 & 8,3 & 2,6 & 24,4 & 1,54
\end{tabular}

С а попель

\begin{tabular}{l|l|l|l|l|l}
60,3 & 100,0 & 54,0 & 7,6 & 5,2 & 33,2
\end{tabular} 1,69 


\section{Методика анализа}

Битумоиды извлекали в аппарате Сокслета смесью бензола и метанола (3:1 по объему) непосредственно из сухих измельченных проб сапропеля (битумоид А) и после удаления растворимых в воде и в $2 \%$-ной $\mathrm{HCl}$ веществ (битумоид C). Битумоиды охарактеризованы элементным составом (табл. 1). Омыление битумоида и выделение кислот были проведены согласно [3].

Газохроматографический анализ метиловых эфиров (МЭ) кислот битумоидов А и С (этерифицированы диазометаном) проведен на хроматографе ЛХМ8-МД (модель 5) на наполненных колонках с неподвижными фазами различной полярности: LAC2-R-446 и апьезон $L$.
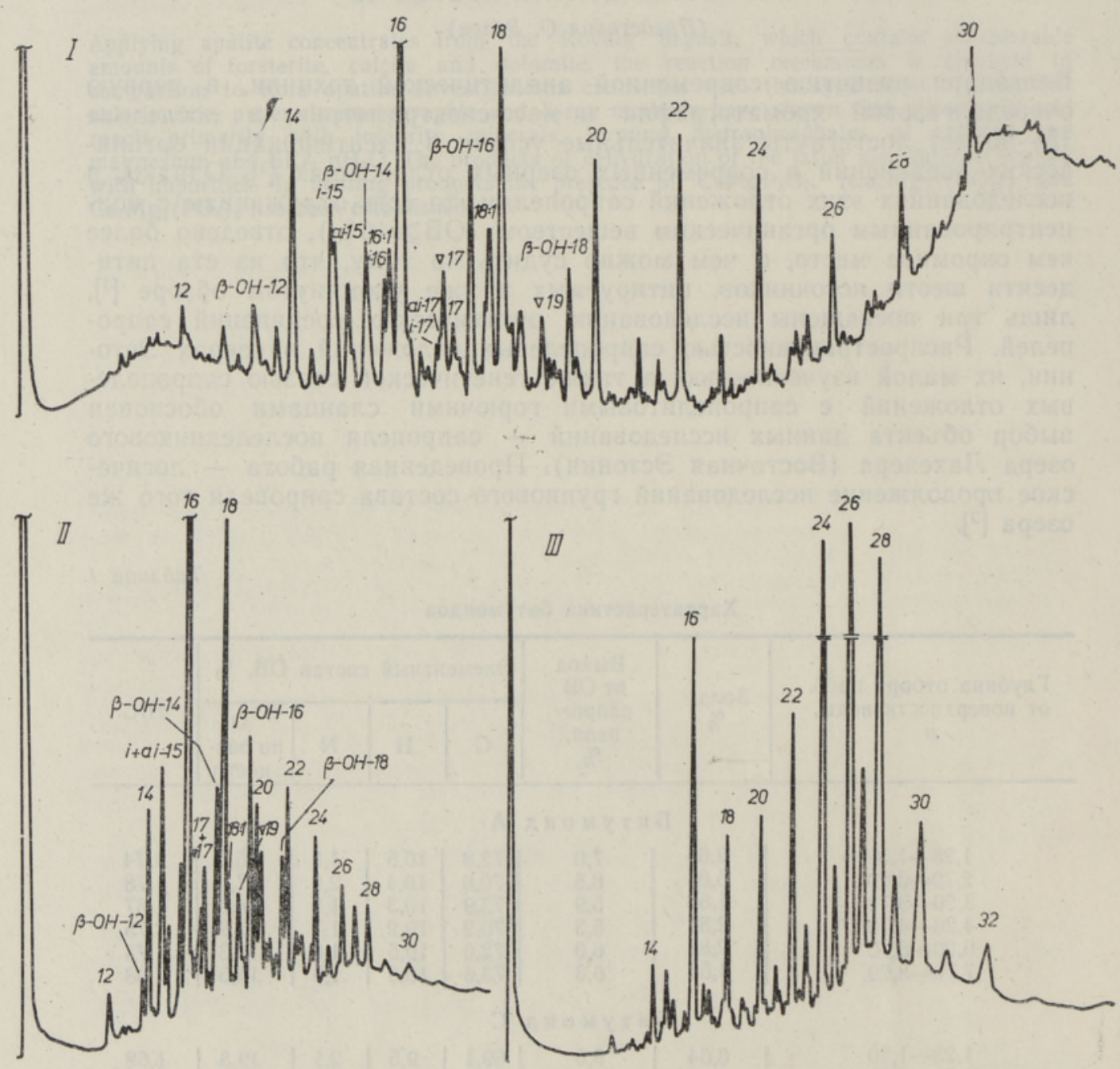

Рис. 1. Хроматограммы МЭ кислот битумоидов C (I, II) и A (III) сапропеля интервала 2,7-3,2 м. Условия анализа: I - стеклянная капиллярная колонка $25 \mu \times 0,2$ мм, неподвижная фаза OV-101, программирование температуры от 120 до $280^{\circ} \mathrm{C}$, скорость 2 град/мин, температура испарителя $300^{\circ}$, скорость газа-носителя (гелия) 2 мл/мин; II, III - колонки 1 м $\times 3$ м., 1,5\% LAC2-R-446 на хромосорбе W AW (80-100 меш), программирование температуры от 75 до $225^{\circ}$ со скоростью 4 град/мuн, температура испарителя $300^{\circ}$, газ-носитель гелий, детекторы пламенно-ионизационные. Цифры у пиков соответствуют числу атомов углерода в молекуле кислоты. 
Газохроматографическое разделение на капиллярной колонке выполнено на хроматографе «Hewlett Packard 5840 A». Условия анализа даны на рис. 1. Хромато-масс-спектрометрический анализ проведен в системе: газовый хроматограф «Hewlett Packard $5840 \mathrm{~A}$ » и массспектрометр «Hewlett Packard 5985 A». Колонка стеклянная капиллярная $35 \mu \times 0,2 м \mu$, неподвижная фаза OV-101. Остальные условия аналогичны приведенным на рис. 1 (I). Энергия ионизирующих электронов 70 әв.

\section{Результаты газохроматографического и хромато-масс-спектрометрического анализов}

$\boldsymbol{\mu}$-Монокарбоновые кислоты (MKK) идентифицированы в интервале $\mathrm{C}_{12}-\mathrm{C}_{35}$ (рис. 2), преобладают четные гомологи. Максимум содержания приходится на $\mathrm{C}_{16}$ и $\mathrm{C}_{18}$.

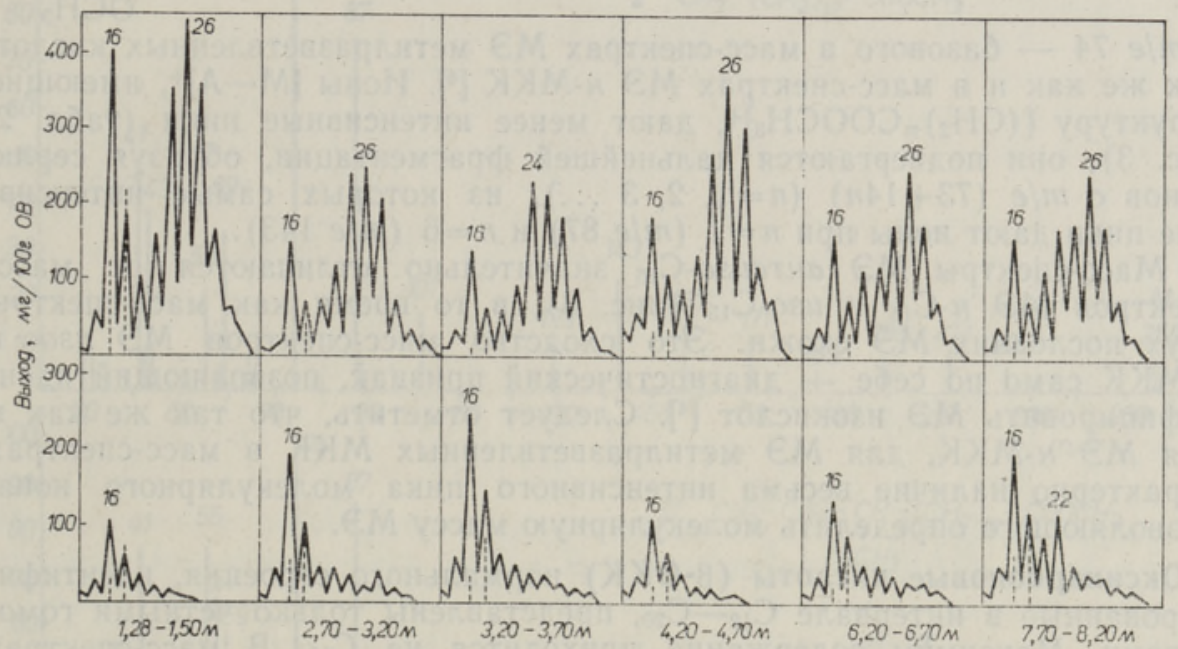

Рис. 2. Диаграммы относительного распределения н-МКК битумоидов А (верхний ряд) и С (нижний ряд) сапропеля, отобранного из различной глубины. Штриховой линией показано содержание ненасыщенных кислот.

Монокарбоновые кислоты изостроения идентифицированы в интервале $\mathrm{C}_{13}-\mathrm{C}_{19}$, преобладают изо- $\mathrm{C}_{15}$ и антеизо- $\mathrm{C}_{15}, \mathrm{C}_{17}$. Под действием электронного удара происходит разрыв цепи молекулы МЭ кислоты изостроения по обе стороны от третичного атома углерода:

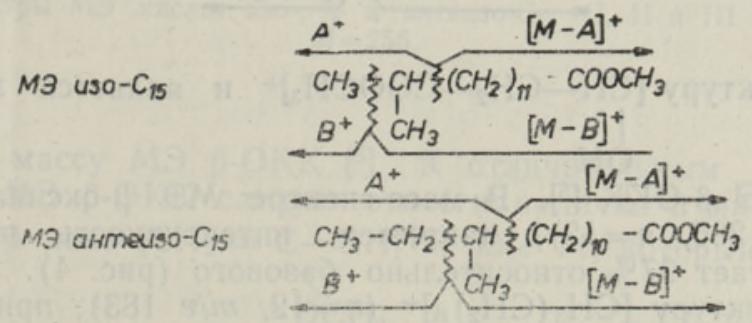

Масс-спектры (рис. 3) указывают на преобладание разрыва со стороны метоксикарбонильной группы. Характеристическими для МЭ изои антеизо- $\mathrm{C}_{15}$ являются ионы $\mathrm{A}^{+}$и $[\mathrm{M}-\mathrm{A}]^{+}$, по массовым числам которых можно определить положение метильного разветвления в цепи 
Относительная интенсивность пиков характеристических нонов МЭ кислот изостроення, \%

\begin{tabular}{|c|c|c|c|c|c|}
\hline \multirow{2}{*}{ МЭ } & \multirow{2}{*}{$M$} & \multicolumn{2}{|c|}{$\mathrm{A}^{+}$} & \multicolumn{2}{|c|}{$[\mathrm{M}-\mathrm{A}]^{+}$} \\
\hline & & $\mathrm{m} / \mathrm{e}$ & $\%$ & $\mathrm{~m} / \mathrm{e}$ & $\%$ \\
\hline 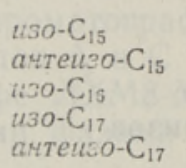 & $\begin{array}{l}256 \\
256 \\
270 \\
284 \\
284\end{array}$ & $\begin{array}{l}43 \\
57 \\
43 \\
43 \\
57\end{array}$ & $\begin{array}{r}100 \\
66 \\
100 \\
100 \\
81\end{array}$ & $\begin{array}{l}213 \\
199 \\
227 \\
241 \\
227\end{array}$ & $\begin{array}{r}20 \\
42 \\
12 \\
12 \\
4\end{array}$ \\
\hline
\end{tabular}

молекулы МЭ. Интенсивность пика $\mathrm{A}^{+}$(табл. 2, рис. 3) конкурирует с интенсивностьо пика перегруппировочного иона $\left[\mathrm{CH}_{2}=\underset{\text { l }}{\mathrm{C}-\mathrm{OH}]}\right.$ : с $m / e 74$ - базового в масс-спектрах МЭ метилразветвленных кислот, так же как и в масс-спектрах МЭ $н$-MKK $\left[{ }^{4}\right]$. Ионы $[M-A]^{+}$, имеющие структуру $\left[\left(\mathrm{CH}_{2}\right)_{n} \mathrm{COOCH}_{3}\right]^{+}$, дают менее интенсивные пики (табл. 2, рис. 3), они подвергаются дальнейшей фрагментации, образуя серию нонов с $m / e(73+14 n) \quad(n=1,2,3 \ldots)$, из которых самые интенсивные пики дают ионы при $n=1(\mathrm{~m} / \mathrm{e} 87)$ и $n=6(\mathrm{~m} / \mathrm{e} 143)$.

Масс-спектры МЭ антеизо- $\mathrm{C}_{15}$ значительно отличаются от массспектров $\mathrm{M} \ni{ }_{15}$ - $\mathrm{C}_{15}$ и $и з о-\mathrm{C}_{15}$ (рис. 3 ), в то время как масс-спектры двух последних МЭ схожи. Это сходство масс-спектров МЭ изо- и н-МКК само по себе - диагностический признак, позволяющий идентифнцировать $M Э$ изокислот [4]. Следует отметить, что так же как и для $M Э$ н-МKК, для $M \ni$ метилразветвленных $M$ КК в масс-спектрах характерно наличие весьма интенсивного пика молекулярного иона, позволяющего определить молекулярную массу МЭ.

$\beta-О$ ксикарбоновые кислоты ( $\beta$-ОКК) нормального строения, идентифицированные в интервале $\mathrm{C}_{12}-\mathrm{C}_{20}$, представлены только четными гомологами. Максимум содержания приходится на $\mathrm{C}_{16}$. В масс-спектрах хроматографических пиков, идентифицированных как $\mathrm{M} \ni \beta-\mathrm{OKK}$, по интенсивности преобладает пик иона с $m / e$ 103. Этот ион $[\mathrm{M}-\mathrm{A}]^{+}$ образуется при разрыве молекулы МЭ $\beta$-ОКК у третичного атома углерода со стороны углеводородного радикала

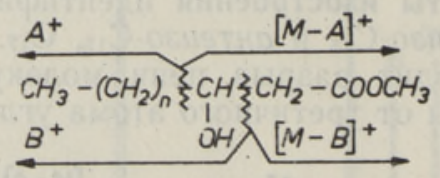

Он имеет структуру $\left[\mathrm{CH}-\mathrm{CH}_{2}-\mathrm{COOCH}_{3}\right]^{+}$и является характеристи-<smiles>O</smiles>

ческим для МЭ $\beta$-ОКК [5]. В масс-спектре МЭ $\beta$-оксипальмитиновой кислоты $(M=286, n=12)$, например, интенсивность пика иона с $\mathrm{m} / \mathrm{e} 103$ достигает $97 \%$ относительно базового (рис. 4). Из иона $\mathrm{A}^{+}$, имеющего структуру $\left[\mathrm{CH}_{3}\left(\mathrm{CH}_{2}\right)_{n}\right]^{+}(n=12, m / e$ 183); при дальнейшей фрагментации образуются ионы той же структуры, но с меньшими массовыми числами. Максимальные пики дают ионы с $m / e \cdot 43(n=2)$ и $m / e 71(n=4)$. Молекулярный ион не дает сигнала в масс-спектрах Мə $\beta$-ОКК, в области тяжелых масс для них характерны пики ионов $[M-18]^{+},[M-50]^{+}$и $[M-92]^{+}$, с помощью которых можно определить 


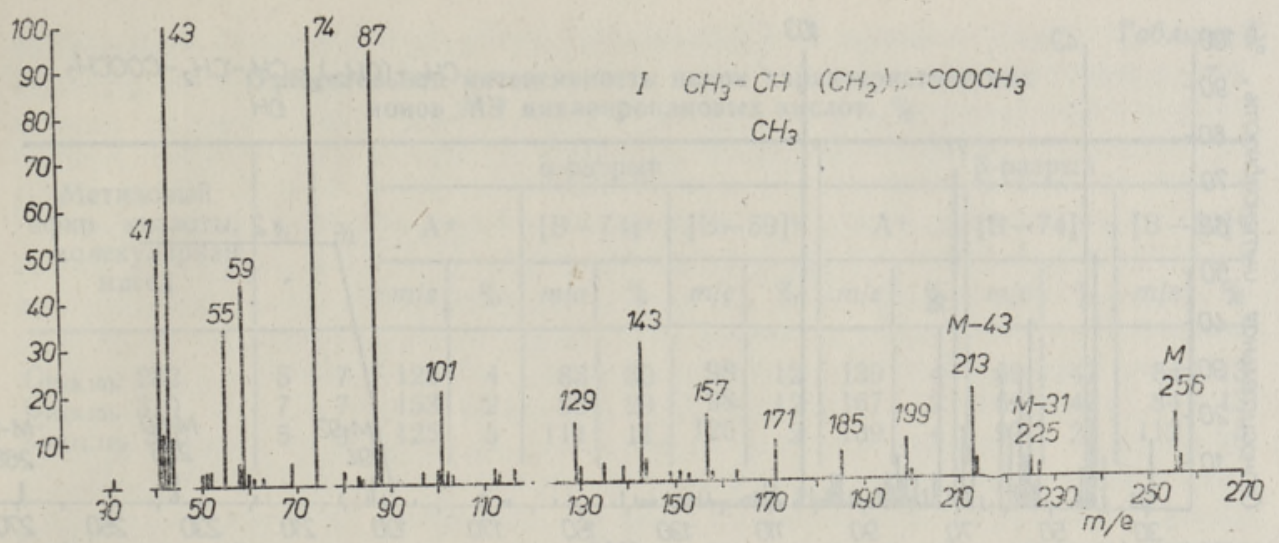

๙०
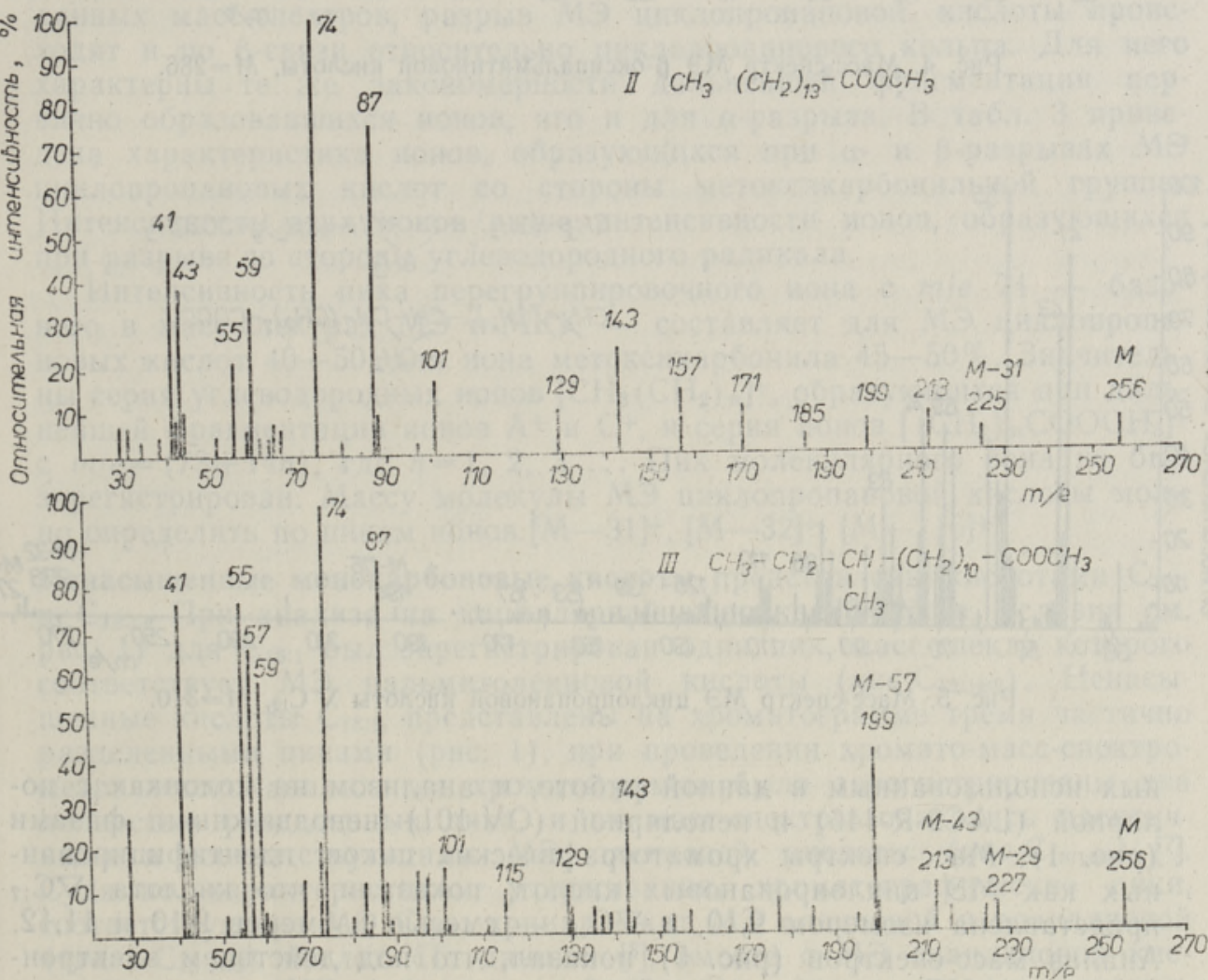

Рис. 3. Масс-спектры МЭ кислот изо-, н- и антеизо- $\mathrm{C}_{15}$. (I, II и III соответственно), $M=256$.

молекулярную массу МЭ $\beta$-ОKК [5]. К отличительным особенностям масс-спектров МЭ $\beta$-ОКК следует отнести наличие в них пика перегруппировочного иона $\left[\mathrm{CH}_{2}=\mathrm{C}-\mathrm{OH}\right] \div$ с $m / e 74$, который отсутствует

в спектрах $\alpha$-OKK. $\mathrm{OCH}_{3}$

Циклопропановые кислоты $\nabla C_{17}$ и $\nabla C_{19}$ были идентифицированы сопоставлением характеристик удерживания с данными работы [ $\left.{ }^{6}\right]$, в которой МЭ этих кислот были анализированы в условиях, аналотич- 


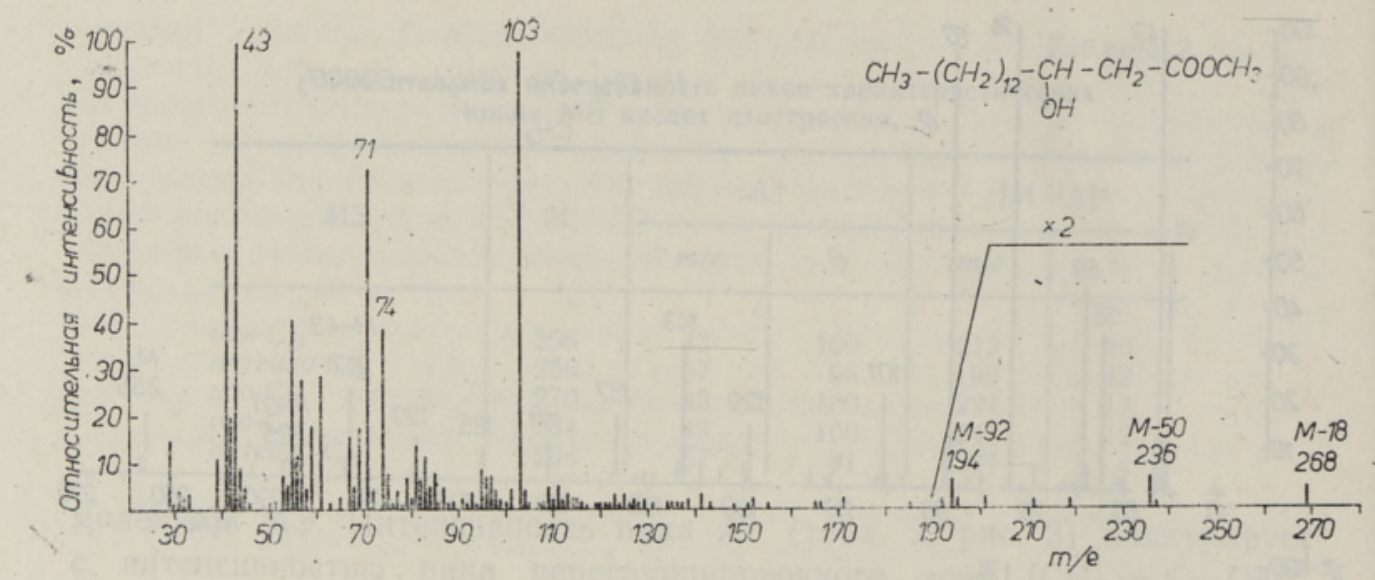

Рис. 4. Масс-спектр МЭ $\beta$-оксипальмитиновой кислоты, $M=286$.

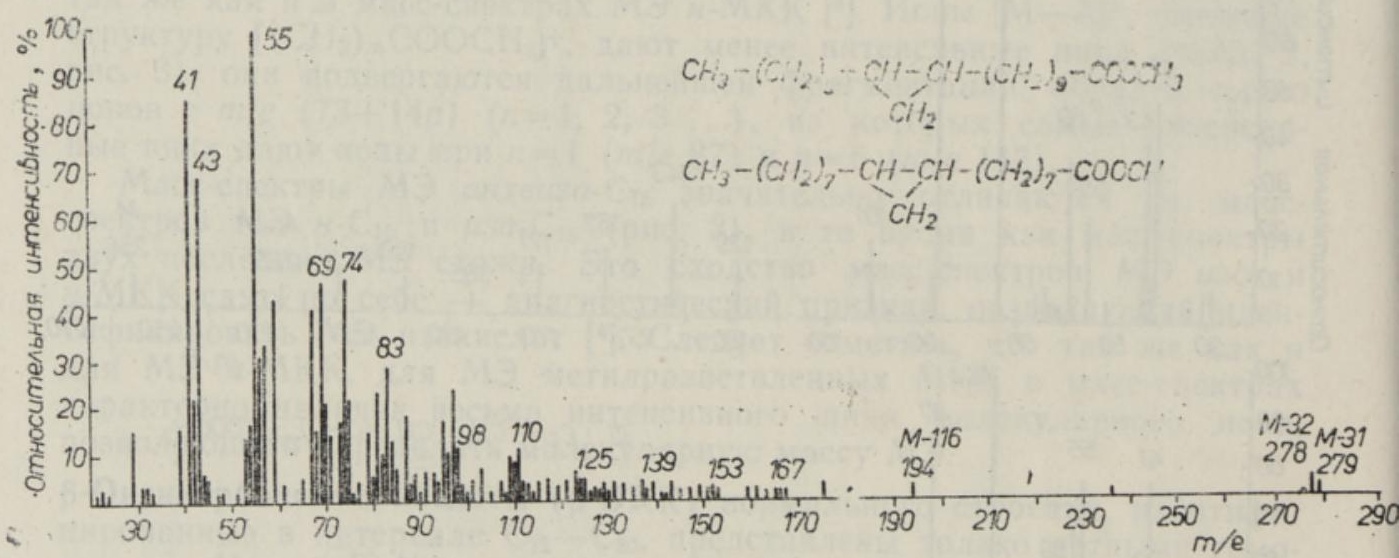

Рис. 5. Масс-спектр МЭ циклопропановой кислоты $\nabla \mathrm{C}_{19}, M=310$.

ных использованным в данной работе, и анализом на колонках с полярной (LAC2-R-446) и неполярной (OV-101) неподвижными фазами (рис. 1). Масс-спектры хроматографических пиков, идентифицированных как MЭ циклопропановых кислот, показали, что кислота $\nabla \mathrm{C}_{\mathrm{i} 7}$ представлена изомером 9,10 , а $\nabla \mathrm{C}_{19}-$ смесью изомеров 9,10 и 11,12 . Анализ масс-спектров (рис. 5) показал, что под действием электронного удара МЭ циклопропановой кислоты

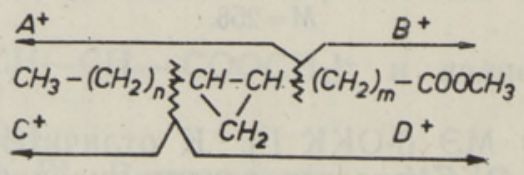

подвергается диссоциативной ионизации по $\alpha$-связи относительно циклопропанового кольца, т. е. у третичного атома углерода. При этом преобладает разрыв со стороны метоксикарбонильной группы. С последующим распадом первично образовавшихся ионов $\mathrm{B}^{+}$и $\mathrm{D}^{+}$связано появление в масс-опектре интенсивных пиков ионов [B-59] $]^{+},[\mathrm{B}-74]^{+}$, $[\mathrm{D}-59]^{+}$и $[\mathrm{D}-74]^{+}$, образующихся при элиминировании метоксикарбонила $(m / e 59)$ и перегруппировочного иона с $m / e$ 74. Как следует из 
Относительная интенсивность пиков характеристических ионов МЭ циклопропановых кислот, \%

\begin{tabular}{|c|c|c|c|c|c|c|c|c|c|c|c|c|c|c|}
\hline \multirow{3}{*}{$\begin{array}{c}\text { Метиловый } \\
\text { эфир кнслоты, } \\
\text { молекулярная } \\
\text { масса }\end{array}$} & \multirow{3}{*}{$n$} & \multirow{3}{*}{$m$} & \multicolumn{6}{|c|}{$\alpha$-разрыв } & \multicolumn{6}{|c|}{$\beta$-разрыв } \\
\hline & & & \multicolumn{2}{|c|}{$\mathrm{A}^{+}$} & \multicolumn{2}{|c|}{$[\mathrm{B}-74]^{+}$} & \multicolumn{2}{|c|}{$[\mathrm{B}-59]^{+}$} & \multicolumn{2}{|c|}{$\mathrm{A}^{+}$} & \multicolumn{2}{|c|}{$[\mathrm{B}-74]^{+}$} & \multicolumn{2}{|c|}{$[B-59]^{+}$} \\
\hline & & & $m / e$ & $\%$ & $\mathrm{~m} / \mathrm{e}$ & $\%$ & $m / e$ & $\%$ & $m / e$ & $\%$ & $m / e$ & $\%$ & $m / e$ & $\%$ \\
\hline $\begin{array}{l}C_{17(9,10)}, 282 \\
C_{19(9,10)}, 310 \\
C_{19(11,12)}, 310\end{array}$ & $\begin{array}{l}5 \\
7 \\
5\end{array}$ & $\begin{array}{l}7 \\
7 \\
9\end{array}$ & $\begin{array}{l}125 \\
153 \\
125\end{array}$ & $\begin{array}{l}4 \\
2 \\
5\end{array}$ & $\begin{array}{r}83 \\
83 \\
111\end{array}$ & $\begin{array}{l}30 \\
29 \\
11\end{array}$ & $\begin{array}{r}98 \\
98 \\
126\end{array}$ & $\begin{array}{r}12 \\
12 \\
2\end{array}$ & $\begin{array}{l}139 \\
167 \\
139\end{array}$ & $\begin{array}{l}4 \\
2 \\
4\end{array}$ & $\begin{array}{l}69 \\
69 \\
97\end{array}$ & $\begin{array}{l}47 \\
47 \\
23\end{array}$ & $\begin{array}{r}84 \\
84 \\
112\end{array}$ & $\begin{array}{r}13 \\
13 \\
5\end{array}$ \\
\hline
\end{tabular}

данных масс-спектров, разрыв МЭ циклопропановой кислоты происходит и по $\beta$-связи относительно циклопропанового кольца. Для него характерны те же закономерности дальнейшей фрагментации первично образовавшихся ионов, что и для $\alpha$-разрыва. В табл. 3 приведена характеристика ионов, образующихся при $\alpha$ - и $\beta$-разрывах МЭ циклопропановых кислот со стороны метоксикарбонильной группы. Интенсивность этих ионов выше интенсивности ионов, образующихся при разрыве со стороны углеводородного радикала.

Интенсивность пика перегруппировочного иона с $m / e 74$ - базового в масс-спектрах МЭ $н$-МКK - составляет для МЭ циклопропановых кислот 40-50, для иона метоксикарбонила $45-50 \%$. Значительны серия углеводородных ионов $\left[\mathrm{CH}_{3}\left(\mathrm{CH}_{2}\right)_{n}\right]^{+}$, образующихся при дальнейшей фрагментации ионов $\mathrm{A}^{+}$и $\mathrm{C}^{+}$, и серия ионов $\left[\left(\mathrm{CH}_{2}\right)_{n} \mathrm{COOCH}_{3}\right]^{+}$ с $m / e=(73+14 n)$, где $n=1,2,3 \ldots$ Пик молекулярного иона не был зарегистрирован. Массу молекулы МЭ циклопропановой кислоты можно определить по пикам ионов $[M-31]^{+},[M-32]^{+},[M-116]^{+}$.

Ненасыщенные монокарбоновые кислоты представлены кислотами $\mathrm{C}_{16: 1}$ и $\mathrm{C}_{18: 1}$. При анализе на капиллярной колонке $(l=25 \mu$, условия см. рис. 1) для $\mathrm{C}_{16: 1}$ был зарегистрирован один пик, масс-спектр которого соответствует $M \ni$ пальмитолеиновой кислоты (цис- $\left.\mathrm{C}_{16: 1 \omega 9}\right)$. Ненасыщенные кислоты $\mathrm{C}_{18: 1}$, представлены на хроматограмме тремя частично разделенными пиками (рис. 1), при проведении хромато-масс-спектрометрнческого анализа на хроматограмме были зарегистрированы два полностью разделенных пика, и их масс-спектры оказались идентичными и соответствующими МЭ олеиновой кислоты (цис- $\left.\mathrm{C}_{18: 1 \omega 9}\right)$ [7]. Судя по характеристикам удерживания, хроматографические пики, соответствующие $M \ni \mathrm{C}_{18: 1}$, принадлежат $M \ni$ олеиновой и эландиновой

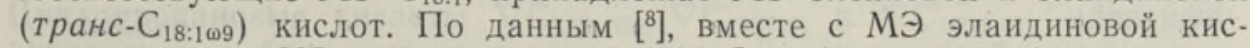

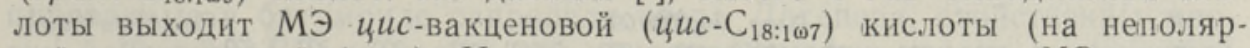
ной неподвижной фазе). Но на основании масс-спектров МЭ ненасыщенных кислот нельзя определить положение двойной связи и стереохимию их молекул. Для этой цели необходим предварительный перевод их в метоксильные производные или анализ другими физическими методами $[9,10]$.

\section{Обсуждение результатов и выводы}

Общая характеристика битумоидов (табл. 1) показывает, что по сравнению с исходным сапропелем они содержат незначительное количество минеральных веществ (выход золы из битумоида А $1,59-5,08$, из битумоида $\mathrm{C}$ еще ниже $-0,64-1,52 \%)$. Битумоиды по сравнению с исходным ОВ сапропеля значительно обогащены углеродом и водородом за счет более низкого содержания в них гетероатомов, особенно 
это касается битумоида А. Содержание азота в битумоидах еще достаточно высокое. Различия в выходах и составах битумоидов могут быть отражением изменений условий в процессе осадконакопления.

Исходя из имеющихся представлений о формах нахождения карбоновых кислот в осадках [11] можно сделать вывод о том, что в условиях выбранного традиционного группового анализа сапропеля $\left.{ }^{2}\right]$ в битумоид A перешли свободные кислоты (RCOOH), кислоты в виде сложных эфиров (RCOOR'), а также часть кислот, связанных с матрицей (решеткой) керогена сложноэфирной связью, но освобожденных при обменном превращении под влиянием метанола (RCOO-решетка $+\mathrm{CH}_{3} \mathrm{OH} \rightleftarrows \mathrm{RCOOCH}_{3}+\mathrm{HO}$-решетка). На долю битумоида С остались в основном кислоты, связанные по ионному типу (соли или комплексы с глинистыми минералами $\mathrm{RCOO}^{-} \mathrm{M}^{+}$). Часть солей низших монокарбоновых кислот должна теряться в водных экстрактах. Не переходит в битумонды и часть кислот, связанных с нерастворимым в органических растворителях ОВ, в том числе с так называемыми гуминовыми кислотами сапропеля, доля которых в отложениях сапропеля озера Лахепера, как предполагается в [ $\left.{ }^{2}\right]$, диагенетически возрастает с увеличением глубины.

Насыщенные $\boldsymbol{H}$-монокарбоновые кислоты. Бимодальное распределение и-MKК (рис. 2, битумоид А), как для современных озерных, так и для морских отложений, указывает, по общепринятому мнению, на их смешанное происхождение $[1,12] . \quad-M K K \leqslant C_{20}$ с максимумами содержания $\mathrm{C}_{16}$ и $\mathrm{C}_{18}$ считаются автохтонными (т. е. происходят из водорослей и бактерий), гомологи $>\mathrm{C}_{20}$ с максимумом для кислот $\mathrm{C}_{24}, \mathrm{C}_{26}$ или $\mathrm{C}_{28}$ считаются аллохтонными (из высших растений). Но если быть очень точными, то часть кислот $\mathrm{C}_{16}$ и $\mathrm{C}_{18}$ следует считать аллохтонными, так как высшие растения содержат достаточно много кислот $\leqslant \mathrm{C}_{20}$, а некоторая часть кислот $>\mathrm{C}_{20}$ может иметь бактериальное и дрожжевое происхождение. Именно с длинноцепочечными кислотамн бактерий и дрожжей можно связать наличие кислот $>\mathrm{C}_{20}$ в битумонде и керогене древних ордовикских горючих сланцев, во время отложения которых высшая наземная растительность отсутствовала.

Исследование отложений высокогорного (абсолютная высота 4180 м) озера $\left[{ }^{13}\right]$ показало, что аллохтонные $H$-MKK $>\mathrm{C}_{20}$ - нензбежные компоненты отложений даже таких современных озер, которые практически лишены и притока поверхностных вод, и береговой растительности. Это означает, что с появлением в силуре наземной растительности среди отложений озерного происхождения трудно найти чистые

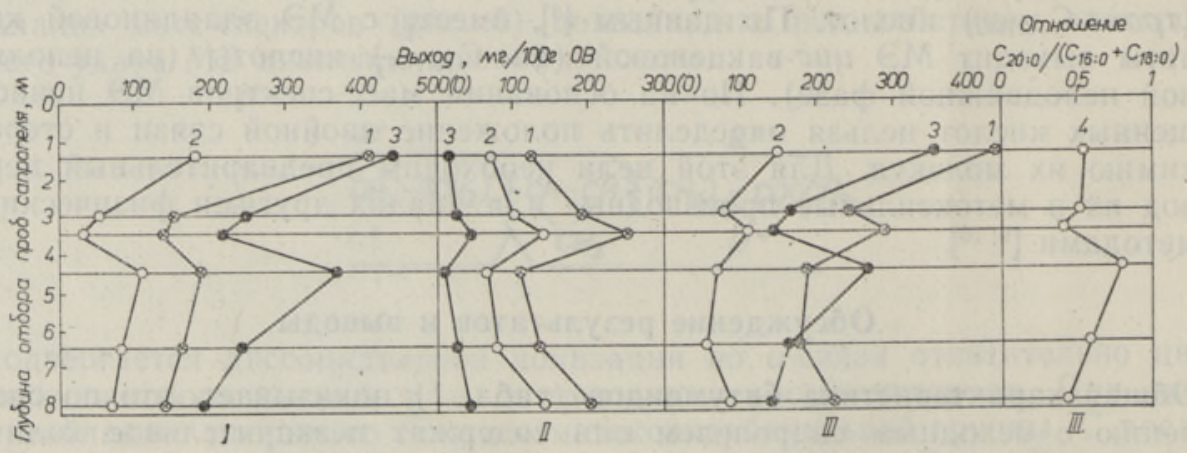

Рис. 6. Кривые изменения содержания кислот $\mathrm{C}_{16: 0}$ (1), $\mathrm{C}_{18: 0}$ (2) и $\mathrm{C}_{26: 0}$ (3) в битумондах $\mathrm{A}, \mathrm{C}$ и $(\mathrm{A}+\mathrm{C})$ (I, II и III соответственно) и изменения отношения $\mathrm{C}_{26: 0} /\left(\mathrm{C}_{16: 0}+\mathrm{C}_{18: 0}\right)$ (4) в битумонде $(\mathrm{A}+\mathrm{C})$ в зависимости от глубины отбора проб сапропеля. 
сапропелиты, в том числе сапропелитовые горючие сланцы. В этом аспекте отложения современных озер (в том числе озеро Лахепера) можно рассматривать как начальную стадию преобразования органического вещества от почти чистых сапропелей до озерных сапропелитогумитов.

При таком рассмотрении на первый план выступает вопрос о том, какие изменения в содержании отдельных химических соединений можно принять за диагенетические, какие из этих изменений связаны с видовыми изменениями организмов данного водоема и какая часть этих соединений участвует в образовании озерных отложений. При рассмотрении данных рис. 6 можно заключить, что в компонентном составе $н$-MKK как битумоида $\mathrm{A}$, так и $\mathrm{C}$ по профилю сапропеля отсутствуют какие бы то ни было направленные изменения. Но кислоты битумоида А во всех изученных интервалах отмечены явным влиянием аллохтонных компонентов по сравнению с кислотами битумоида С. Что касается суммарного выхода $н$-MKK $\mathrm{C}_{12}-\mathrm{C}_{35}$, то он самый высокий для верхнего интервала сапропеля $(3,4 \%$ на ОВ), а для остальных интервалов он колеблется от 1,9 до $2,2 \%$. Изменение состава кислот по глубине сапропеля показано кривыми изменения количества нанболее характерных для различных биопродуцентов кислот $\mathrm{C}_{16}, \mathrm{C}_{18}$ и $\mathrm{C}_{26}$ (рис. 6). Характер этого изменения сложный, для битумоидов $\mathrm{A}$ и С противоположный. Суммарная кривая для кислоты $\mathrm{C}_{26}$, по все́й вероятности, отражает изменения вклада высшей растительностинв формирование ОВ сапропеля. В этом случае, судя по отношению $\mathrm{C}_{26} /\left(\mathrm{C}_{16}+\mathrm{C}_{18}\right)$ (рис. 6), наибольший относительный вклад высшей растительности должен был иметь место во время отложения сапропеля в интервале $4,2-4,7$ м.

Монокарбоновые кислоты изостроения $\mathrm{C}_{13}-\mathrm{C}_{19}$, идентифицированные в составе кислот битумоида сапропеля, указывают на участие бактерий в преобразовании ОВ сапропеля. Кислоты подобного диапазона характерны как аэробным [14], так и анаэробным видам [15]. Максимум содержания обычно приходится на кислоты изо- и антеизо- $\mathrm{C}_{15}$, что отмечено и для изокислот исследованного битумоида (рис. 1). Важность идентификации кислот изо- $\mathrm{C}_{15}, \mathrm{C}_{17}$ и антеизо- $\mathrm{C}_{15}, \mathrm{C}_{17}$ подчеркивается их использованием в целях таксономической классификации микроорганизмов [ ${ }^{16,17]}$. Общее количество этих кислот в битумоюде $(\mathrm{A}+\mathrm{C})$ - почти постоянное, что может быть связано с относительной постоянностью микробиальных процессов в сапропеле, но их колинество в битумоидах А и С, так же, как и количество $H$-MKK, изменяется диаметрально противоположно (рис. 7).

Циклопропановые кислоты $\nabla C_{17(9,10),} \nabla C_{19(9,10)}$ и $\nabla C_{19(11,12)}$, идентйфи: цированные в битумоиде сапропеля озера Лахепера, свойственны многим бактериям $\left[{ }^{18}\right]$, но целый ряд циклопропановых кислот, в том числе $\nabla C_{19(9,10)}\left[{ }^{19}\right]$, содержится в высших растениях. Поэтому только но содержанию $\nabla C_{19(11,12)}$ - уникальной для микроорганизмов кислоты - можно сделать вывод об участии бактериального материала в формировании битумоида изучаемого сапропеля (рис. 7). Возможным биологическим предшественником этого изомера можно считать нена-

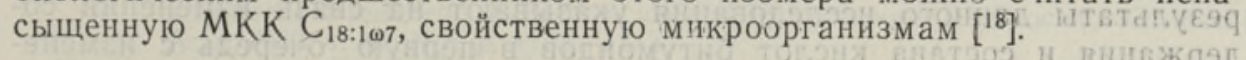
$\beta-0$ ксикарбоновые кислоты $\mathrm{C}_{12}-\mathrm{C}_{20}$, содержащие только четные гомо логи, как и циклопропановые, - единственные компоненты, колияество которых увеличивается с глубиной отбора пробы сапропелян(рис. 7): Эти кислоты свойственны бактериям $\left[{ }^{18,20}\right]$, их высшие ромодоги $\mathrm{C}_{18 \text { и }}$ $\mathrm{C}_{20}$ - некоторым дрожжам [21]. Высшие растения в отличие от бажтерий содержат преимущественно $\alpha$ - и $\omega$-оксикислоты, в морской праве найдены в небольших количествах и $\beta$-оксикислоты $\mathrm{C}_{12}-\mathrm{C}_{\text {q }}\left[{ }^{22}\right]$ 


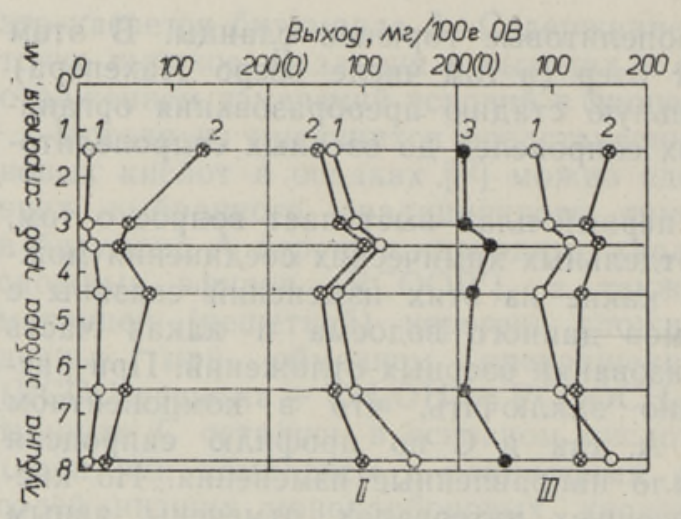

Рис. 7. Кривые изменения содержания кислот $\left(\beta\right.$-окси- $\mathrm{C}_{16}+\beta$-окси- $\left.\mathrm{C}_{18}\right)$ (1), (изо-, антеизо- $\mathrm{C}_{15}+$ изо-, антеизо- $\left.\mathrm{C}_{17}\right)$ (2) и $\nabla \mathrm{C}_{19}$ (3) в битумоидах A, C и $(\mathrm{A}+\mathrm{C})$ (I, II и III соответственно) в зависимости от глубины отбора проб сапропеля.

Поэтому идентифицированные $\beta$-оксикислоты можно считать дополнительным свидетельством постоянного бактериального вклада в ОВ сапропеля.

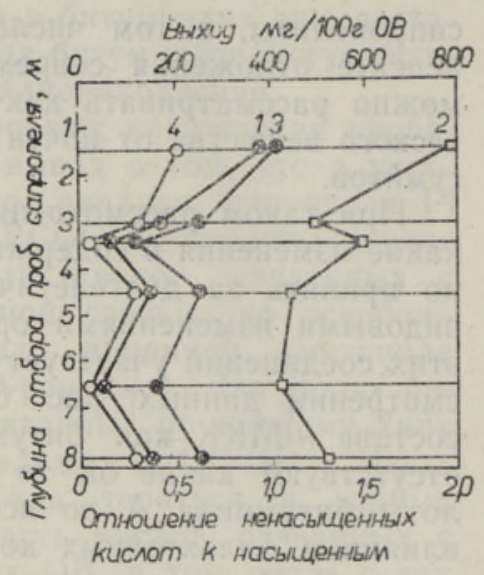

Рис. 8. Кривые изменения содержания кислот $\left(\mathrm{C}_{16: 1}+\mathrm{C}_{18: 1}\right)$ (1) и $\left(\mathrm{C}_{16: 0}+\mathrm{C}_{18: 0}\right)$ (2) и изменения отношений $\mathrm{C}_{18: 1} / \mathrm{C}_{18: 0}$ (3) и $\left(\mathrm{C}_{16: 1}+\mathrm{C}_{18: 1}\right) /\left(\mathrm{C}_{16: 0}+\mathrm{C}_{18: 0}\right)$ (4) в битумоиде $(\mathrm{A}+\mathrm{C})$ в зависимости от глубнны отбора проб сапропеля.

Ненасыщенные монокарбоновые кислоты в современных осадках обычно по относительному распределению сходны с насыщенными кислотами. Причем короткоцепочечные ненасыщенные кислоты связывают с автохтонными (водорослевыми и бактериальными) источниками, а длинноцепочечные - c аллохтонным материалом высших растений [']. В битумоидах сапропеля озера Лахепера были идентифицированы только низшие ненасыщенные кислоты $\mathrm{C}_{16: 1}$ и $\mathrm{C}_{18: 1}$, крнвая изменения содержания которых (за исключением интервала $3,2-3,7$ м) похожа на кривую насыщенных кислот $\mathrm{C}_{16}$ и $\mathrm{C}_{18}$, но отношения $\mathrm{C}_{18: 1} / \mathrm{C}_{18: 0}$ и $\left(\mathrm{C}_{16: 1}+\mathrm{C}_{18: 1}\right) /\left(\mathrm{C}_{16: 0}+\mathrm{C}_{18: 0}\right)$ изменяются по сложной кривой, причем уменьшение этих отношений, связанное с диагенетическими изменениями ОВ сапропеля, недостаточно явно выражено (рис. 8). По всей вероятности, эти диагенетические изменения в содержании и распределении ненасыщенных кислот, если они имели место, замаскированы изменениями под влиянием условий осадкообразования, что наблюдалось при исследовании, например, осадка озера Бива $\left[{ }^{23}\right]$.

Если полученные ранее результаты исследований по выявлению изменений группового состава ОВ сапропеля озера Лахепера в зависимости от глубины на фоне изменений условий осадконакопления позволили заметить и раннедиагенетические изменения осадочного ОВ (увеличение отношения $\mathrm{C} / \mathrm{N}$, уменьшение содержания легкогидролизуемых веществ с одновременным увеличением содержания «гуминовых веществ» с увеличением глубины отбора проб сапропеля [2]), то результаты данного исследования указывают на связь изменений содержания и состава кислот битумоидов в первую очередь с изменениями условий осадконакопления и в меньшей мере - с диагенетическими изменениями ОВ сапропеля. Поэтому послойное исследование кислот битумоидов термически непревращенных осадочных отложений может оказаться ключевым в понимании изменений условий осадконакопления и влияния этих изменений на структуру ОВ.

Авторы благодарят Ю. Денисова и Г. Осипова за снятие массспектров. 
1. Barnes, M. A., Barnes, W. C. Organic compounds in lake sediments. - In. Lakes. Chemistry, Geology, Physics. New York, Heidelberg, Berlin, 1978, p. 127152.

2. П алу В., Вески Р. Об изменении группового состава сапропеля озера Лахепера в зависимости от глубины. - Изв. АН ЭССР. Хим., 1982, т. 31, № 2, c. $136-140$.

3. Palu, V., B ondar, J., Veski, R., Fomina, A. n-Alkanes, monocarboxylic and $\alpha, \omega$-dicarboxylic acids in the extracts of Mandra oil shale. - Compt. rend. Acad. Bulg. Sci., 1979 , v. 32 , N 4, p. 505-508.

4. A pon, J.M. B., Nicolaides, N. The determination of the position isomers of the methyl branched fatty acid methyl esters by capillary GC/MS. - J. Chromatogr. Sci., 1975 , v. $13, \mathrm{~N} 10$, p. $467-473$.

5. Ryhage, R., Stenhagen, E. Mass spectrometric studies. VI. Methyl esters of normal chain oxo-, hydroxy-, methoxy-, and epoxy-acids. - Arkiv Komi, 1960, v. 15 , N 50 , p. $545-574$.

6. Андреев Л. В., Немировская И. Б., Томащук А. Ю., Никитин Д. И., $\mathrm{X}$ м ельницкий $\mathrm{P}$. А. Оценка вклада различных микроорганизмов в формирование липидного пула почв. - В кн.: Бносинтез и метаболизм липидов у микроорганизмов. М., 1979 , с. $243-246$.

7. Atlas of Mass Spectral Data. New York, London, Sidney, Toronto, 1969, v. 3.

8. Van Vleet, E. S., Qu in n, J. G. Early diagenesis of fatty acids and isoprenoid alcohols in estuarine and coastal sediments. - Geochim. Cosmochim. Acta, 1979, v. 43, N 3, p. $289-303$.

9. Matsuda, H., Koyama, T. Positional isomer composition of monounsaturated fatty acids from a lacustrine sediment. - Geochim. Cosmochim. Acta, 1977, v. $41, \mathrm{~N} 2$, p. $341-345$.

10. Plattner, R. D., Kleima n, R. Grevillea robusta seed oil a source of $\omega-5$ monoenes. - Phytochemistry, 1977, v. 16, N 2, p. 255-256.

11. Эглинтон Дж. Органическая геохимия (подход химика-органика). - В кн.: Органическая геохимия. Л., 1974 , с. $13-62$.

12. Simoneit, B. R. T., Mazurek, M. A., Brenner, S., Crisp, P. T., Kapla n, I. R. Organic geochemistry of recent sediments from Guaymas Basin, Gulf of California. - Deep-Sea Res., 1979, v. 26A, N 8, p. 879-891.

13. Simoneit, B. R. T., H a lpern, H. I., D i d y k, B. M. Lipid productivity of a high Andean lake. - In: Biogeochemistry of Ancient and Modern Environments. Canberra, New York, 1980 , p. $201-210$.

14. K a neda, T. Fatty acids in the genus Bacillus. 1. Iso- and anteiso-fatty acids as characteristic constituents of lipids in 10 species. - J. Bacteriol., 1967, v. 93, N 3, p. 894-903.

15. Ueta, N., Ishizuka, L., Yamakawa, T. Gas chromatographic grouping of bacteria. - In: Proceedings of the First International Conference of Culture Collections University of Tokyo. Tokyo, 1970, p. 371-381.

16. Kramzar, G. R., L y $\mathrm{mch}$, D. L. A qualitative and quantitative study of the fatty acid composition of selected microorganisms. - Microbios, 1976, v. 17, N 1, p. $7-16$.

17. Биосинтез и метаболизм липидов у микроорганизмов. М., 1979.

18. Perry, G. J., Volkman, J. K., Johns, R. B. Fatty acids of bacterial origin in contemporary marine sediments. - Geochim. Cosmochim. Acta, 1979, v. 43, N 11, p. $1715-1725$.

19. Яновская Л. Я., Домбровский В. А., Хусид А. Х. Циклопропаны с функциональными группами. М., 1980.

20. Ки п и инова Е. А., Касянчук Н. В., 3 ах арова И. Я. Сравнительное изучение жирнокислотного состава клеток и липосахарндов различных вндов бактерий рода Pseudomonas. - В кн.: Биосинтез и метаболизм липидов у микроорганизмов. М., 1979 , с. $43-46$.

21. 3 а лашко М. В., Р ом анов а Л. В. Влияние некоторых ингибиторов обмена на рост и образование липидов дрожжей Rh. glutinis. 35. - В кн.: Бносинтез и метаболизм липидов у микроорганизмов. М., 1979, с. 35-37.

22. Volkman, J. K., Johns, R. B., Gilla n, F. T., Perry, G. J. Microbial lipids of an intertidal sediment. 1. Fatty acids and hydrocarbons. - Geochim. Cosmochim. Acta, 1980, v. 44, N 8, p. 1133-1143.

23. Kawamura, K., Is hiwat a ri, R. Polyunsaturated fatty acids in a lacustrine sediment as a possible indicator of paleoclimate. - Geochim. Cosmochim. Acta, 1981 , v. 45 , N 2, p. $149-155$.

Институт химии

Академии наук Эстонской ССР
Поступила в редакцию $2 / \mathrm{X} 1981$ 
Jevgenia BONDAR, Vilja PALU, R. VESKI

\section{LAHEPERA JÄRVE SAPROPEELI A- JA C-BITUMOIDI ORGAANILISTE HAPETE KOOSTISE MUUTUMISEST SUGAVUTI}

Artiklis on esitatud gaasi-vedelikkromatograafia ja kromatomassispektromeetria andmed sirge ahelaga küllastunud $\left(\mathrm{C}_{12}-\mathrm{C}_{35}\right)$ ja küllastumata monokarboksüül- $\left(\mathrm{C}_{16: 1}, \mathrm{C}_{18: 1}\right)$, isoja anteiso-monokarboksüül- $\left(\mathrm{C}_{13}-\mathrm{C}_{19}\right), \beta$-oksükarboksüül- $\left(\mathrm{C}_{12}-\mathrm{C}_{20}\right)$ ja tsüklopropaankarboksüülhapete sisalduse kohta Lahepera järve sapropeeli bitumoidis. Oletatakse, et erinevused nende hapete kogustes ja vahekorras on eeskätt seotud sapropeeli moodustumise tingimustega.

Eugenie EONDAR, Vilja PALU, R. VESKI

\section{DEPTH-DEPENDENT DISTRIBUTION OF ORGANIC ACIDS IN THE BITUMOIDS A AND C OF SAPROPEL OF LAKE LAHEPERA}

Data are presented on the application of gas-liquid chromatography and gas chromatography-mass spectrometry to the investigation of the composition variation of organic acids of bitumoid of sapropel (average organic matter content in sapropel is. $37.4 \%$ ) of a small (100 ha) post-glacial L. Lahepera (Estonian SSR) with a depth of about $7 \mathrm{~m}$. The aliphatic saturated $n$-monocarboxylic acids $\mathrm{C}_{12}-\mathrm{C}_{35}$, mono-unsaturated $n$-monocarboxylic acids $\mathrm{C}_{16}$ and $\mathrm{C}_{18}$, iso- and anteiso-monocarboxylic acids $\mathrm{C}_{13}-\mathrm{C}_{19}$, $\beta$-hydroxy acids $\mathrm{C}_{12}-\mathrm{C}_{20}, 9,10$-cyclopropane acids $\mathrm{C}_{17}$ and $\mathrm{C}_{19}$ and 11,12-cyclopropane acid $\mathrm{C}_{19}$ vere identified. As believed, the composition variation and amount of the identified acids depend on the variations in environmental conditions of sedimentation rather than on the diagenesis of the organic matter of sapropel, a complex system of bioand geoorganic matter. 